\title{
Parental Support during Childhood Predicts Life History-Related Personality Variation and Social Status in Young Adults
}

\author{
Aaron W. Lukaszewski
}

Published online: 27 March 2015

(C) Springer International Publishing 2015

\begin{abstract}
Adaptationist theories of development posit the existence of facultative mechanisms designed to calibrate individual differences in life history strategy to cues available in childhood. Such theories have led to the discovery of links between parenting-related cues and multiple life history phenotypes in offspring (e.g., reproductive timing), but less is known about the influences of parental behavior on the development of stable personality traits. This article reports a preliminary test of the hypothesis that life history-related personality variation is developmentally calibrated in response to the level of parental support received during childhood. Consistent with this, in a sample of young adults $(N=321)$, (i) subjects' reports of their parents' income positively predicted the level of parental support they recall having received during childhood; (ii) these measures of parental income and parental support in childhood positively predicted subjects' standing on the general factor of personality (GFP), long-term mating orientation, and prestige-based social status; and (iii) path analyses fit a model of the following form: parental income $\rightarrow$ parental support in childhood $\rightarrow \mathrm{GFP} \rightarrow$ prestigebased status. Moreover, these effects held when controlling for perceptions of current social support, which implies that associations of parental support in childhood with outcomes in adulthood did not reflect current perceptions or global selfevaluative biases. These findings, though preliminary, are consonant with recent theories positing that the GFP and prestige-based status reflect individual differences along a fast-slow life history continuum, and suggest that life history-related personality variation may be developmentally calibrated to parental support during childhood.
\end{abstract}

\footnotetext{
A. W. Lukaszewski $(\bowtie)$

Department of Psychology, Oklahoma State University,

116 N. Murray, Stillwater, OK 74074, USA

e-mail: aaron.lukaszewski@okstate.edu
}

Keywords Evolutionary psychology $\cdot$ Facultative calibration $\cdot$ General factor of personality $\cdot$ Life history theory Prestige $\cdot$ Social status

The extent to which parenting has enduring effects on offspring personality development and related life outcomes has long been a question of central interest in psychology and developmental science. However, despite decades of research into the correlates of parenting styles and tactics (Darling and Steinberg 1993), conflicting findings and theoretical disagreements have prevented the formation of a general consensus regarding what specific role - if any - parental behavior plays in shaping children's stable personality characteristics (Bugental 2000; Harris 1995, 2011; Plomin et al. 2013; Raby et al. 2015). This ambiguity highlights the importance of theories that can generate testable, a priori predictions about the specific links between aspects of parental behavior and offspring personality development.

Recent adaptationist theories provide a powerful framework within which to understand effects of early experiences on personality development. Broadly speaking, these models are based on the premise that interindividual variation in developmental trajectories may be orchestrated, in part, by facultative adaptations designed to calibrate behavioral phenotypes in response to cues that have reliably predicted optimal trait levels over human evolutionary history (Buss 2009; Del Giudice et al. 2015; Ellis et al. 2009; Frankenhius and Panchanathan 2011; Lukaszewski and Roney 2011; Penke 2011; Nettle et al. 2013; Tooby and Cosmides 1990). In theory, such cue-based developmental mechanisms would have been selected for as they outcompeted alternative variants (e.g., genetically fixed phenotypes) by improving the functional match between phenotypic strategies and individual circumstances. 
In identifying specific cues to which phenotypic variation should be calibrated over development, recent research has increasingly drawn upon life history theory (Ellis et al. 2009; Figueredo et al. 2014; Del Giudice et al. 2015; Kaplan et al. 2009; Roff 2002). From this standpoint, phenotypic variation often reflects the existence of alternative strategies for allocating limited resources in a way that optimally negotiates fundamental tradeoff decisions faced by organisms, such as whether to invest in present versus future reproduction, mating versus parenting effort, and the quality versus quantity of offspring. For example, if exposed to cues indicative of being born into a harsh (i.e., high mortality) environment, it would have been adaptive for human ancestors to calibrate toward a life history strategy that entails reproducing early and often, rather than investing in an uncertain future (Belsky et al. 1991; Brumbach et al. 2009; Crisholm et al. 2005; Ellis et al. 2009; Figueredo et al. 2011; McCullough et al. 2012; Vigil et al. 2005).

To date, research undertaken from this perspective has led to the discovery of adaptively patterned associations of various parenting-related cues (e.g., father absence, household conflict) with life history phenotypes in offspring, including age at reproductive maturity (Maestripieri et al. 2004), promiscuity (Brumbach et al. 2009), age at first reproduction (Vigil et al. 2005), social deviance (Brumbach et al. 2009), and expected lifespan (Crisholm et al. 2005). Relatively little is known, however, about how cues present in parental behavior may influence the development of variation in children's normal (i.e., nondisordered) personality (Carver et al. 2014; Jonason et al. 2014; Raby et al. 2015), such as that captured by the "Big Five" personality dimensions (John et al. 2008). The time is ripe for this issue to be explored, given that the variance shared by the Big Five dimensions - the general factor of personality (GFP) - has recently been interpreted to reflect individual differences in life history strategy (Dunkel et al. 2012; Figueredo et al. 2011, 2014; Rushton et al. 2008; van der Linden et al. 2012).

The current article reports a preliminary test of the hypothesis that the level of parental support received during childhood acts as a cue to which life history-related personality variation (indexed by the GFP and long-term mating orientation) is calibrated in ontogeny. In addition, because investment in cooperative relationships and social status has also been viewed in life history perspective, I examine the association of parental support during childhood with prestige-based social status in adulthood, and I test whether this association is mediated via life history-related personality variation.

\section{Parental Support During Childhood $\rightarrow$ Life History-Related Personality Variation and Social Status}

As is true for cross-species comparisons (Roff 2002), withinspecies variation in life history strategy can be conceptualized along a fast-slow continuum (Ellis et al. 2009; Figueredo et al. 2014; Del Giudice et al. 2015; Kaplan et al. 2009; Roff 2002). Fast life history strategies entail accelerated growth, early reproductive maturation, emphasis on offspring quantity, and a focus on exploiting material and social resources in support of current reproduction. Slow life history strategies, conversely, are characterized by delayed growth and reproduction, emphasis on promoting offspring quality, and an orientation toward cultivating long-term cooperative relationships that represent investments in future reproduction. In general, fast life history strategies are more adaptive in harsh or unpredictable environments wherein resources are scarce and mortality is high, whereas slow life history strategies are more adaptive in higher-quality environments wherein investments in personal and social capital are relatively likely to yield a net return in the future (Del Giudice et al. 2015; Ellis et al. 2009; Figueredo et al. 2014; Kaplan et al. 2009; Roff 2002). For example, slow life history strategies are defined in part by the orientation toward investing in long-term romantic bonds characterized by relative monogamy and cooperative investment in offspring (Figueredo et al. 2014) - a mating strategy that is most adaptive in stable environments wherein one's romantic partner and offspring are relatively likely to avoid premature death and achieve consistent success in resource accrual (Belsky et al. 1991; Ellis et al. 2009).

The GFP has also been theorized to reflect individual differences along the fast-slow life history continuum. At the level of phenotypic description, the GFP captures the variance that is shared by the Big Five personality dimensions: Agreeableness, Conscientiousness, Emotional Stability, Extraversion, and Openness to Experience (Figueredo et al. 2014; Rushton et al. 2008; van der Linden et al. 2010b). Theoretically, being high on the GFP reflects a slow life history strategy characterized by investment in multiple domains of social life, for example, the cultivation and maintenance of cooperative relationships (high agreeableness; extraversion), the tendency to follow local norms and policies (high conscientiousness), and the motivation to attain positions of high status and leadership (high extraversion; conscientiousness). Making investments in these aspects of social life typically entails paying immediate personal costs in the service of long-term social and reproductive rewards, including the formation of cooperative alliances that buffer against occasional periods of illness or bad luck in foraging (Sugiyama and Scalise-Sugiyama 2003) and facilitate the cultivation of high social status (Price and Van Vugt 2014; von Rueden et al. 2008). Consistent with this interpretation, the GFP has been found to predict various indicators of prosociality, social success, and status - outcomes that theoretically enhance future reproduction (Dunkel and van der Linden 2014; Figueredo et al. 2014; van der Linden et al. 2010a,b, 2012).

The primary hypothesis of the current study is based on the premise that the level of parental support received during 
childhood would have ancestrally predicted variable world states that are functionally relevant for the calibration of an individual's life history strategy as reflected in the GFP and one's orientation toward long-term mating relationships. Specifically, if the developing child's parents are both able and willing to invest heavily in the embodied capital of offspring, this should probabilistically indicate having been born into a relatively high-quality environment wherein it is adaptive to invest in future reproduction via long-term cooperative relationships and an emphasis on offspring quality-i.e., to adopt a slow, growth-oriented life history strategy (Belsky et al. 1991; Carver et al. 2014; McCullough et al. 2012; van der Linden et al. 2012; Weaver et al. 2007). If so, natural selection may have favored developmental mechanisms designed to calibrate life history-related personality variation to the level of parental support received in childhood and throughout development.

It also follows from this hypothesis that parental support received during childhood will predict later social outcomes that are influenced by life history-related personality variation. As noted above, recent theories of human life history evolution have characterized the orientation toward engaging in cooperative relationships and status pursuit as costly investments in future reproduction (e.g., Ellis et al. 2009; Figueredo et al. 2014; Kaplan et al. 2009; McCullough et al. 2012; Price and Van Vugt 2014; von Rueden et al. 2008). Thus, given evidence that the GFP positively predicts social effectiveness and status (Dunkel and van der Linden 2014; van der Linden et al. 2010a,b), the positive association between parental support in childhood and later social status may be mediated by life history-related personality variation as indexed by the GFP. However, this hypothesis does not apply equally to social status that is attained by generating benefits for others (i.e., prestige-based status) and that sought by aggressively intimidating others (i.e., dominance-based status) (see Cheng et al. 2010). In particular, given the association of slow life histories with prosocial behavioral strategies, the parental support $\rightarrow \mathrm{GFP} \rightarrow$ social status link is only expected to obtain for prestige-based status.

\section{Predictions of the Present Study}

The present study provides a preliminary test of these developmental-adaptationist hypotheses. To this end, a sample of young adults provided estimates of their parents' household incomes (a determinant of modern parents' ability to invest in offspring), as well as retrospective assessments of the overall level of support they received from their parents while growing up (which is reflective of both the ability and willingness to invest in offspring). In addition, subjects completed scales assessing life history-related personality variation (the GFP and long-term mating orientation), as well as dominance- and prestige-based social status.

Subjects also completed a scale measuring their current perceived level of social support from friends and family. This was important for two reasons. First, to the degree that a slow life history strategy entails adopting a prosocial orientation toward investment in cooperative relationships and status, current social support, the GFP, long-term mating orientation, and prestige-based social status should be positively intercorrelated (Dunkel et al. 2012; Figueredo et al. 2014; Manson 2015). Second, because it is plausible that subjects' current level of social support would bias their retrospective assessments of the parental support they received while growing up (cf. Carver et al. 2014), it is important to demonstrate that retrospectively assessed parental support predicts life history-related personality variation and social status when controlling for perceptions of current social support. If the predicted parental support $\rightarrow \mathrm{GFP} \rightarrow$ status effects still obtain when controlling for current social support, this would bolster the interpretation of these associations as evidence of developmental calibration, as opposed to artifacts of response biases (e.g., a global tendency to assume that people value and support oneself).

The expectation that parental support in childhood, current social support, the GFP, and long-term mating orientation will be positively intercorrelated is consistent with the existence of a broad life history component, which has been referred to psychometrically as the "Super-K" factor (e.g., Figueredo et al. 2014). As such, the current study also computed such a factor in order to examine its association with parental income and prestige-based social status, which were expected to be positive.

In sum, the arguments outlined above suggest six specific predictions to be tested with the correlational data from the current study:

1. Parental income will positively predict parental support in childhood.

2. Parental income and parental support in childhood will positively predict subjects' standing on the GFP and long-term mating orientation, respectively.

3. The GFP will positively predict subjects' prestige-based (but not dominance-based) social status.

4. Given predictions 1-3, parental income and parental support in childhood will positively predict subjects' prestige-based status, and this association will be mediated by the GFP.

5. Current social support will correlate positively with parental income, parental support in childhood, long-term mating orientation, the GFP, and prestige-based status. However, the mediational effects entailed by prediction 4 will hold even when controlling for current social support. 
6. Parental support in childhood, current social support, the GFP, and long-term mating orientation will load onto a common principal component, a Super-K factor, which will be positively correlated with parental income and prestige-based status.

\section{Methods}

\section{Subjects}

Subjects were 321 undergraduates (200 women; $M$ age= $18.90, \mathrm{SD}=1.41$ ) from a large public university on the west coast of the USA who participated in exchange for partial course credit. The sample's ethnic breakdown was as follows: $58.9 \%$ white, $18.4 \%$ Hispanic, $10.3 \%$ Asian, $2.8 \%$ African American, and $9.6 \%$ other.

\section{Measures}

All subjects completed a paper-and-pencil questionnaire battery in a large auditorium during the same 60-min session. Items for all variables other than parental income were rated on Likert-type scales from 1 to 7. Operational definitions for the focal variables were as follows.

Parental income was measured via subjects' selection of one of the following annual household income categories: less than $\$ 25,000 ; \$ 25,00-\$ 75,000 ; \$ 75,000-\$ 150,000$; more than $\$ 150,000$. Because there were relatively few subjects who selected the highest or lowest categories, this variable was dichotomized by collapsing the lower and higher two income categories into low parental income $(n=127)$ and high parental income $(n=194)$.

Parental support in childhood was measured via a composite based on subjects' ratings of 12 items assessing different aspects of parental support they received in childhood $(\alpha=.83)$ : "Growing up, how close were you with your parents compared with others?;" "Growing up, how close were you with your mother?;" Growing up, how comfortable were you talking to your mother about issues?;" "Growing up, could you count on your mother no matter what?;" "Growing up, how often did you mother attend your activities?;" "Growing up, how much time did you spend with your mother?;" "Growing up, how close were you with your father?;" "Growing up, how comfortable were you talking to your father about issues?;" "Growing up, could you count on your father no matter what?;" "Growing up, how often did you father attend your activities?;" "Growing up, how much time did you spend with your father?;" and "Looking back, how would you rate your parents as providers of resources while you were growing up?"

GFPs were computed based on scores from the short-form IPIP NEO-PI-R (http://ipip.ori.org/), which includes ten items to assess each of the Big Five dimensions: Agreeableness $(\alpha=.84)$, Conscientiousness $(\alpha=.87)$, Emotional Stability $(\alpha=.86)$, Extraversion $(\alpha=.89)$, and Openness to Experience $(\alpha=.78)$. Three different versions of the GFP were computed. First, I conducted a principal components analysis wherein the big five trait scores were forced to load onto a single component (see van der Linden et al. 2010a,b, 2012). The first (unrotated) component explained $34 \%$ of the total variance in the solution, and factor loadings were .72 for Agreeableness, .73 for Openness, .64 for Extraversion, .39 for Conscientiousness, and .36 for Emotional Stability. These loadings were then employed to compute a "sample-based" GFP. Second, because some have argued that GFPs based on factor loadings from individual subject samples are suboptimal (van der Linden et al. 2010a,b), I computed another "meta-based" GFP score for each subject that was weighted by the factor loadings reported by van der Linden et al.'s (2010b) metaanalysis, which were .57 for Agreeableness, .42 for Openness, .57 for Extraversion, .63 for Conscientiousness, and .62 for Emotional Stability. Finally, because studies have failed to extract a GFP from the HEXACO personality structure (Ashton et al. 2009) - a six factor model of personality that is an alternative to the Big Five structure - I also included a composite indented to tap life history-related personality variation that is reflected in the HEXACO traits. Specifically, Manson (2015) recently reported that, within the HEXACO space, measures of life history strategy are most strongly associated with Extraversion, Conscientiousness, and Agreeableness (dimensions with very similar locations in factor space across HEXACO and Big Five rotational structures). As such, I followed Manson (2015) in computing a unitweighted Extraversion-Conscientiousness-Agreeableness (E-C-A) composite based on these three dimensions. This latter $\mathrm{E}-\mathrm{C}-\mathrm{A}$ composite is not technically a true GFP and is not referred to as such. However, its inclusion should facilitate comparison with past and future research that employs the HEXACO dimensions rather than the Big Five. In the analyses reported below, it made little difference which of these personality composites was employed, which is unsurprising given that the sample- and meta-based GFPs were strongly intercorrelated at $r=.95$, and the $\mathrm{E}-\mathrm{C}-\mathrm{A}$ composite correlated with both GFPs at $r=.88$.

Long-term mating orientation $(\alpha=.87)$ was assessed via the ten-item scale developed and validated by Jackson and Kirkpatrick (2007). Example items include "I hope to have a romantic relationship that lasts the rest of my life" and "Finding a long-term romantic partner is not important to me" (reverse-scored).

Dominance- and prestige-based social status, respectively, were measured with the dominance-prestige scale (Buttermore 2006; see also Cheng et al. 2010). Dominancebased status $(\alpha=.79)$ is measured by eight items, for example, "I am willing to use aggressive tactics to get my way." 
Prestige-based status ( $\alpha=.87)$ is also measured by eight items, for example, "I have gained distinction and social prestige among my peers."

Current social support was measured with an eight-item scale adapted from Pierce et al. (1991) Counting on Your Social Network scale $(\alpha=.89)$ : Example items include: "Can you count on your friends and family to help in a time of tragedy?," "How much do your friends value you?," and "How much do your family members value you?."

\section{Results}

Zero-order correlations were first computed among all measured variables, including the Big Five dimensions within the GFP. These zero-order effects were consistent with all six predictions (Table 1). Parental income was positively correlated with parental support in childhood. In turn, both of these variables were positively correlated with subjects' scores on the sample-based GFP, meta-based GFP, E-C-A composite, and current social support. Parental support in childhood also positively predicted long-term mating orientation and prestige-based social status, although the zero-order correlations of parental income with these variables did not reach significance. Additionally, the GFPs (and E-C-A composite), current social support, long-term mating orientation, and prestige-based status were all positively intercorrelated. Generally, the GFPs (and E-C-A composite) were more strongly correlated with the other focal variables in the study than were any of the individual personality dimensions whose shared variance comprises the GFP.

Fisher $r$-to- $Z$ transformation tests were employed to explore whether these zero-order correlations differed in magnitude between the sexes. Sex did not significantly moderate any of the correlations $(Z s<1.10, p s>.20)$. Consistent with this, as shown beneath the diagonal in Table 1, controlling for subject sex did not alter the correlational patterns. As such, all further analyses were collapsed across men and women.

Because the GFP and long-term mating orientation were correlated aspects of life history-related personality variation, it was of interest to determine whether these variables exhibited independent associations with parental support in childhood. When controlling for long-term mating orientation, parental support remained significantly correlated with the (meta-based) GFP (partial $r=.25, p<.001$ ). When controlling for the GFP, however, parental support was no longer significantly correlated with long-term mating orientation (partial $r=.09, p=.11$ ). Thus, the relationship between parental support in childhood and personality was largely captured by that reflected in the GFP.

Next, multivariate path analyses were employed to examine the hypothesized mediational effects, which are depicted in Fig. 1. Specifically, the hypothesized model posits a causal

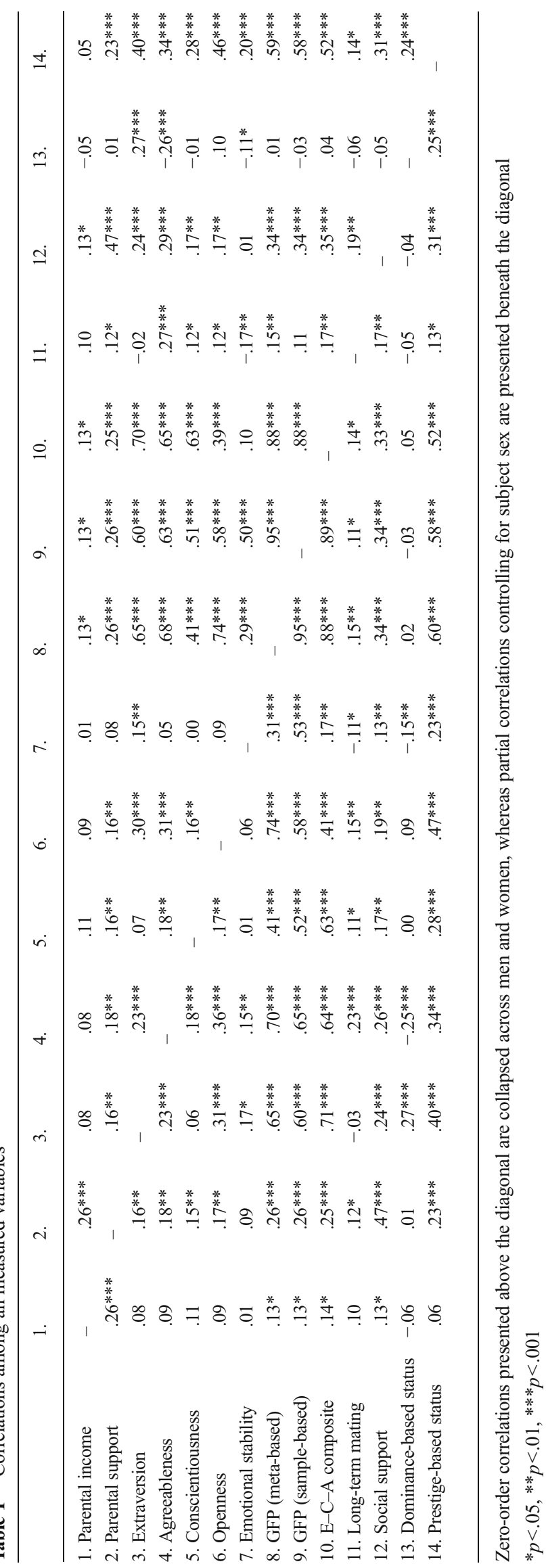


Fig. 1 Path model testing all predicted direct and indirect effects. Solid arrows indicate associations that are hypothesized as causal; dotted lines indicate hypothesized correlations between variables. Light shaded boxes represent variables in childhood; dark shaded boxes represent outcomes in adulthood. All effect sizes are standardized path coefficients. ${ }^{*} p<.05$; $* * p<.01 ; * * * p<.001$

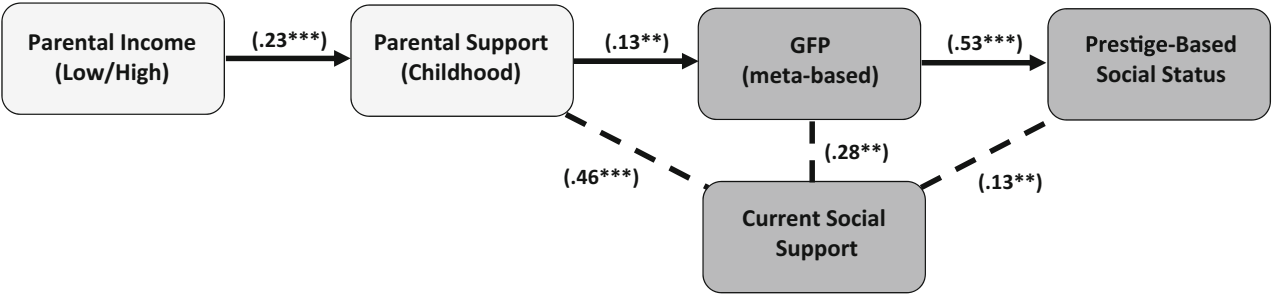

Indirect Paths

Income $\rightarrow$ Parental Support $\rightarrow$ GFP

Income $\rightarrow$ Parental Support $\rightarrow$ GFP $\rightarrow$ Prestige

Parental Support $\rightarrow$ GFP $\rightarrow$ Prestige
Standardized Effect $(95 \% \mathrm{Cl})$

$$
\begin{aligned}
& .03 *(.01-.07) \\
& .02 *(.00-.04) \\
& .08 *(.01-.15)
\end{aligned}
$$

chain of the following form: parental income $\rightarrow$ parental support in childhood $\rightarrow \mathrm{GFP} \rightarrow$ prestige-based status. In addition, to control for current social support, this variable was included in the model and permitted to correlate with parental support in childhood, the meta-based GFP, and prestige-based status. This model was computed in AMOS, with standardized direct and indirect effects estimated via maximum likelihood bootstrapping techniques (5000 bootstrap iterations) and $95 \%$ bias-corrected confidence intervals (Kline 2005).

The specified model (Fig. 1) provided an excellent fit to the data, $\chi^{2}(4)=4.67, p=.32, \mathrm{CFI}=.99, \mathrm{RMSEA}=.02(90 \% \mathrm{CI}$, $.00-.09)$. All direct effects were statistically significant, consistent with the zero-order correlations. Indirect effects (Fig. 1, inset) supported all predictions: Parental income had an indirect effect on the GFP that was mediated via parental support in childhood, and this effect also mediated an association of parental income with prestige-based status that ran all the way through the model. These direct and indirect effects all held even while controlling for current social support, which was correlated with all mediators and outcomes.

Given that parental support in childhood, current social support, the GFP, and long-term mating orientation were positively intercorrelated (Table 1), it was appropriate to compute a broad life history (i.e., Super-K) factor representing the shared variance among these variables (Figueredo et al. 2014). To this end, I conducted a principal components analysis wherein these four variables loaded onto a common factor, which explained $45 \%$ of the total variance in the solution. Factor loadings were .80 for current social support, .74 for parental support in childhood, .67 for the (meta-based) GFP, and .44 for long-term mating orientation. As predicted, the resulting Super-K composite was positively correlated with parental income $(r=.23, p<.001)$ and prestige-based status $(r=.48, p<.001)$, but not with dominance-based status $(r=$ $-.05, p=.42$ ). (Results were extremely similar when using the sample-based GFP or E-C-A composite, respectively, rather than the meta-based GFP.)

Finally, given the putative importance of the GFP in explaining associations of life history-related developmental cues with social outcomes in adulthood, it was of interest to examine whether the individual Big Five dimensions exhibited unique associations with the other focal variables above and beyond the GFP. To this end, I computed partial correlations of the Big Five traits with the other variables in the study that controlled for the sample-based GFP (Table 2). None of the Big Five dimensions exhibited unique associations with parental income, parental support in childhood, or current social support. However, in these analyses, long-term mating orientation was positively predicted by Agreeableness, and negatively predicted by Extraversion and Emotional Stability; dominance-based status was positively predicted by Extraversion and negatively predicted by Agreeableness and Emotional Stability; and prestige-based status was negatively predicted by Agreeableness. In sum, some of the Big Five traits explained incremental variance in status- and mating-related variables in adulthood, consistent with prior research (e.g., Cheng et al. 2010; van der Linden et al. 2010b). However, none of the variables tapping parental support in development or social support were uniquely correlated with the Big Five above and beyond the GFP.

Table 2 Associations of the Big Five dimensions with life history and status variables when controlling for the sample-based GFP

\begin{tabular}{lccccc}
\hline & $\mathrm{A}$ & $\mathrm{C}$ & $\mathrm{E}$ & $\mathrm{ES}$ & $\mathrm{O}$ \\
\hline Parental income & .00 & .05 & -.01 & -.03 & -.02 \\
Parental support & .00 & .05 & -.01 & .02 & -.04 \\
Social support & .04 & .04 & .02 & .03 & -.10 \\
Long-term mating & $.17^{* *}$ & .03 & $-.17^{* *}$ & $-.17^{* *}$ & .05 \\
Dominance-based status & $-.37^{* * *}$ & -.01 & $.34^{* * *}$ & $-.17^{* *}$ & .10 \\
Prestige-based status & $-.14^{* *}$ & .05 & .02 & .05 & .05 \\
\hline
\end{tabular}

Analyses control for subject sex, but are nearly identical when sex is not controlled. Results are likewise unchanged when controlling for the metabased GFP or E-C-A composite rather than the sample-based GFP

$A$ Agreeableness, $C$ Conscientiousness, $E$ Extraversion, ES Emotional stability, $O$ Openness to Experience

${ }^{*} p<.05, * * p<.01, * * * p<.001$ 


\section{Discussion}

Results from the current study provided evidence consistent with the hypothesis that the overall level of parental support received during childhood acts as an evolved cue to which life history-related personality variation is calibrated in ontogeny. Most importantly, subjects' global assessments of the parental support they received while growing up positively predicted their standing on the GFP, long-term mating orientation, current social support, and prestige-based social status in early adulthood. Additionally, path analyses fit a causal model wherein parental support calibrates life history-related personality variation (the GFP), which in turn results in variable levels of achieved status in adulthood. Moreover, these associations all held when controlling for perceptions of current social support from friends and family; this argues against the idea that the predicted effects were driven by retrospective assessments of parental support in childhood that were biased by current perceptions or a global self-positivity/negativity bias (cf. Carver et al. 2014).

The current findings join other recent studies in pointing to the potential importance of parental support in the developmental calibration of human personality. For example, multiple recent studies have found that childhood adversity—one component of which is low parental support-is positively correlated with individual differences in anger, aggression, exploitativeness, impulsivity, and future discounting, and negatively correlated with agreeableness, prosociality, and secure romantic attachment (Brumbach et al. 2009; Carver et al. 2014; Crisholm et al. 2005; Griskevicius et al. 2011; Jonason et al. 2014; McCullough et al. 2012; Pedersen et al. 2014). Similarly, Raby et al. (2015) recently reported that measures of early maternal sensitivity - a specific facet of parental support - prospectively predicted overall social competence and educational attainment in offspring across three decades. Additionally, these predictive effects of early maternal sensitivity did not weaken across development, which is consistent with the idea that parental support in childhood has enduring (as opposed to diminishing) effects on personality and related outcomes (Raby et al. 2015). All of the developmental outcome variables in these studies should be expected to covary with the fast-slow life history continuum as indexed by the GFP (see Figueredo et al. 2014), but this is the first study to examine received parental support in childhood (or any parenting-related developmental cue) in relation to the GFP and prestige-based status in adulthood. The diversity of ways in which early adversity and parental support have been defined across these studies highlights the need for future research that attempts to hone in on the specific cues that are employed by facultative mechanisms in the calibration of life history strategy.

Research on nonhuman species also attests to the importance of parental resources and behavioral support as calibrators of life history strategy in offspring. For example, in the rhesus macaque, life history-related aspects of infant temperament and growth trajectory are programmed by cues in mother's milk that indicate maternal energetic condition (Hinde et al. 2015). Similarly, in the rat, offspring life history strategy is calibrated by the level of maternal care received in the perinatal period - effects that are known to be partly mediated by influences of maternal care behaviors on the epigenetic demethylation of glucocorticoid receptor (GR) gene sequences (Weaver et al. 2007). Consistent with the hypothesis that the same sorts of effects occur in humans, (i) individuals who were abused by their parents during childhood - an extreme indicator of low parental support - have been found to exhibit similar patterns of GR demethylation to rats who experienced low maternal care (McGowan et al. 2009) and (ii) parent-offspring relationship quality has been found to predict stress-related patterns of glucocorticoid production in offspring (Byrd-Craven et al. 2012). Such parental support $\rightarrow$ demethylation $\rightarrow$ glucocorticoid associations have not yet been linked to life history-related personality variation in humans. As such, future research should examine whether parental support in childhood influences the GFP (and other life history phenotypes) via analogous epigenetic effects on neuroendocrine functioning.

\section{Limitations and Alternative Explanations}

As with many preliminary investigations, the current study was limited in ways that might inform future research examining effects of parental support in childhood on life history variation. Most importantly, although the hypothesis under evaluation is developmental in nature, only cross-sectional data were employed, which meant relying upon broad retrospective assessments of parental income and parental support in childhood. Although it is promising that the predicted patterns were robust when controlling for perceptions of current social support, it will be important for future research to operationalize early parental support in more precise and externally valid ways. Relatedly, the GFP, current social support, and prestige-based status were solely measured via self-report. The scales tapping these constructs have been previously validated, but the findings would be even more convincing if future research were able to find the same patterns using a longitudinal design and a multimethod approach to psychometric assessment.

There has been some debate among psychometricians regarding the phenotypic reality of the correlations among the Big Five dimensions that comprise the GFP. Although some authors have suggested that the GFP may be an artifact of selfpositivity biases (e.g., McCrae et al. 2008), this hypothesis has been subsequently countered with rigorous empirical tests, which suggest a phenotypic reality to the GFP (e.g., Dunkel and van der Linden 2014; van der Linden et al. 2012). 
Nonetheless, as noted above, a GFP is not readily extracted from the HEXACO dimensions, which are rotated somewhat differently than the Big Five traits (Ashton et al. 2009). Because of this, the current study also included an E-C-A composite, which has been shown to correlate quite strongly with a direct measure of life history strategy $(r=.66)$ when personality was assessed with the HEXACO Inventory (Manson 2015). This E-C-A composite was very highly correlated with the sample- and meta-based GFPs, and using this variable instead of the GFPs did not change any of the results reported herein. The extent to which life history variation is correlated with the GFP - versus only certain aspects thereof - is therefore a substantive question for future research.

Even if the phenotypic associations reported in the current study are entirely valid, there are alternative explanations for these patterns that must be acknowledged. First, the proposed model joined previous theory in hypothesizing that effects of early experience on life history calibration are driven by exposure to external cues, such as parental support and environmental harshness (e.g., Belsky et al. 1991; Ellis et al. 2009; Weaver et al. 2007). However, recent theoretical models have raised the possibility that life history strategies are not calibrated directly in response to external environmental cues such as parental behavior, but rather to internal cues that are the consequence of environmental variation (Del Giudice et al. 2015; Nettle et al. 2013; von Rueden et al., submitted for publication). In the current context, this would imply that low parental resources and support have depressive effects on the phenotypic condition of offspring and that life historyrelated personality variation is more directly calibrated to individual condition over development. The data from the present study cannot discriminate between these subtly different adaptationist explanations. It is worth noting, however, that long-term mating orientation - one of the life history-related personality variables in the current study - is not associated with indicators of phenotypic condition in young adults, such as physical attractiveness and physical strength (Lukaszewski et al. 2014).

Another potential alternative explanation for the current findings is that they are driven by heritable variation in life history-related strategy. Consistent with this, the GFP is substantially heritable (Rushton et al. 2008), and adults' standing on the GFP positively predicts their social effectiveness (Dunkel and van der Linden 2014), occupational success (Sitser et al. 2013), and the level of parental support they provide for offspring (van der Linden et al. 2012). Thus, it is logically possible that children with supportive, high-status parents inherit specific genotypes that predispose them to be high on the GFP, which in turn promotes their own social success and prestige-based status. However, it is important to note in this context that large gene association studies (including genome-wide scans) conducted in the postgenomic era indicate that there exist no specific genotypes that reliably explain a detectable portion of the variance in any aspect of human personality (e.g., Service et al. 2012). As such, any genotypes that $d o$ lead to direct genetic transmission of GFP levels from parents to offspring would likely be low frequency alleles being evolutionarily maintained in the context of mutation-selection balance or pathogen-host coevolution (see Lukaszewski and von Rueden 2015). The current data cannot address this alternative hypothesis of direct genetic inheritance, but it will be important for future research to identify the exact mechanism(s) by which individual differences in life history strategy are transmitted across generations.

\section{Conclusions}

The present research preliminarily supported the hypothesis that the level of parental support received during childhood calibrates life history-related personality variation, which in turn influences the cultivation of prestige-based status in adulthood. This study thus joins a growing body of research attesting to the value of adaptationist models in generating predictions regarding associations of early experience with individual differences in life history strategy (Brumbach et al. 2009; Carver et al. 2014; Crisholm et al. 2005; Ellis et al. 2009; McCullough et al. 2012; Raby et al. 2015; Vigil et al. 2005). In addition, the findings are consonant with recent theories characterizing the GFP (Dunkel et al. 2012; Figueredo et al. 2014; van der Linden et al. 2012), social support (Figueredo et al. 2014), long-term mating orientation (Figueredo et al. 2014), and prestige-based status (von Rueden et al. 2008), respectively, as indicators of one's place along a fast-slow life history continuum. Despite these strengths, the current study is subject to potential alternative explanations, and it raises more questions than it answers regarding the conceptualization of parental support and the developmental timescales of life history calibration. As such, we hope this article will stimulate further adaptationist research addressing the specific ways in which parental support in childhood - or some correlated cue - may function as a calibrator of life history-related personality variation that persists into adulthood.

\section{References}

Ashton, M. C., Lee, K., Goldberg, L. R., \& de Vries, R. E. (2009). Higher order factors of personality: Do they exist? Personality and Social Psychology Review, 13, 79-91.

Belsky, J., Strinberg, L., \& Draper, P. (1991). Childhood experience, interpersonal development, and reproductive strategy: An evolutionary theory of socialization. Child Development, 62, 647-670.

Brumbach, B. H., Figueredo, A. J., \& Ellis, B. J. (2009). Effects of harsh and unpredictable environments in adolescence on development of 
life history strategies: A longitudinal test of an evolutionary model. Human Nature, 20, 25-51.

Bugental, D. B. (2000). Acquiring the algorithms of social life: A domain-based approach. Psychological Bulletin, 126, 187-219.

Buss, D. M. (2009). How can evolutionary psychology successfully explain personality and individual differences? Perspectives on Psychological Science, 4, 359-366.

Buttermore, N. (2006). Distinguishing dominance and prestige: Evidence of a self-report scale. Poster presented at the annual meeting of the Human Behavior and Evolution Society, Philadelphia, PA.

Byrd-Craven, J., Auer, B. J., Granger, D. A., \& Massey, A. R. (2012). The father-daughter dance: The relationship between father-daughter relationship and daughters' stress response. Journal of Family Psychology, 26, 87-94.

Carver, C. S., Johnson, S. L., McCullough, M. E., Forster, D. E., \& Joorman, J. (2014). Adult personality correlates of childhood adversity. Frontiers in Psychology. doi:10.3389/fpsyg.2014.01357.

Cheng, J. T., Tracy, J. L., \& Henrich, J. (2010). Pride, personality, and the evolutionary foundations of human social status. Evolution and Human Behavior, 31, 334-347.

Crisholm, J. S., Quinlivan, J. A., Petersen, R. W., \& Coall, D. A. (2005). Early stress predicts age at menarche and first birth, adult attachment, and expected lifespan. Human Nature, 16, 233-265.

Darling, N., \& Steinberg, L. (1993). Parenting style and context: An integrative model. Psychological Bulletin, 113, 487-496.

Del Giudice, M., Gangestad, S. W., \& Kaplan, H. (2015). Life history theory and evolutionary psychology. In D. M. Buss (Ed.), The handbook of evolutionary psychology (2nd ed.). New York: Wiley.

Dunkel, C. S., \& van der Linden, D. (2014). Evidence for the general factor of personality as social-effectiveness. Personality and Individual Differences, 64, 147-151.

Dunkel, C. S., Kim, J. K., \& Papini, J. R. (2012). The general factor of psychosocial development and its relation to the general factor of personality and life history strategy. Personality and Individual Differences, 52, 202-206.

Ellis, B. J., Figueredo, A. J., Brumbach, B. H., \& Schlomer, G. L. (2009). Fundamental dimensions of environmental risk: The impact of harsh versus unpredictable environments on the evolution and development of life history strategies. Human Nature, 20, 204-268.

Figueredo, A. J., Wolf, P. S. A., Gladden, P. R., Olderbak, S., Andrzejczak, D. J., \& Jacobs, W. J. (2011). Ecological approaches to personality. In D. M. Buss \& P. H. Hawley (Eds.), The evolution of personality and individual differences (pp. 210-239). Oxford: Oxford University Press.

Figueredo, A. J., Wolf, P. S. A., Olderbak, S., Gladden, P. R., ..., Rushton, J. P. (2014). The psychometric assessment of human life history strategy: A meta-analytic construct validation. Evolutionary Behavioral Sciences, 8, 148-185.

Frankenhius, W. E., \& Panchanathan, K. (2011). Balancing sampling and specialization: An adaptationist model of incremental development. Proceedings of the Royal Society of London B, 278, 3558-3565.

Griskevicius, V., Tybur, J. M., Delton, A. W., \& Robertson, T. E. (2011). The influence of mortality and socioeconomic status on risk and delayed rewards: A life history theory approach. Journal of Personality and Social Psychology, 100, 1015-1026.

Harris, J. R. (1995). Where is the child's environment? A group socialization theory of development. Psychological Review, 102, 458-489.

Harris, J. R. (2011). Explaining individual differences in personality: Why we need a modular theory. In D. M. Buss \& P. H. Hawley (Eds.), The evolution of personality and individual differences (pp. 121-153). Oxford: Oxford University Press.

Hinde, K., Skibiel, A. L., Foster, A. B., Del Rosso, L., Mendoza, S. P., \& Capitanio, J. P. (2015). Cortisol in mother's milk across lactation reflects maternal life history and predicts infant temperament. Behavioral Ecology, 26, 269-281.
International personality item pool: A scientific collaboratory for the development of advanced measures of personality and other individual differences (http://ipip.ori.org/).

Jackson, J. J., \& Kirkpatrick, L. A. (2007). The structure and measurement of human mating strategies: Toward a multidimensional model of sociosexuality. Evolution and Human Behavior, 28, 382-391.

John, O. P., Naumann, L. P., \& Soto, C. J. (2008). Paradigm shift to the integrative big five trait taxonomy: History, measurement, and conceptual issues. In O. P. John, R. W. Robins, \& L. A. Pervin (Eds.), Handbook of personality psychology: Theory and research (3rd ed., pp. 114-159). New York: Guilford Press.

Jonason, P. K., Lyons, M., \& Bethell, E. (2014). The making of Darth Vader: Parent-child care and the dark triad. Personality and Individual Differences, 67, 30-34.

Kaplan, H., Gurven, M., \& Winking, J. (2009). An evolutionary theory of human lifespan: Embodied capital and the human adaptive complex. In V. Bengston, M. Silverstein, N. Putney, \& D. Gans (Eds.), Handbook of theories of aging (pp. 39-66). New York: Springer.

Kline, R. B. (2005). Principles and practice of structural equation modeling (2nd ed.). New York: Guilford Press.

Lukaszewski, A. W., \& Roney, J. R. (2011). The origins of extraversion: Joint effects of facultative calibration and genetic polymorphism. Personality and Social Psychology Bulletin, 37(3), 409-421.

Lukaszewski, A. W., \& von Rueden, C. R. (2015). The extraversion continuum in evolutionary perspective: A review of recent theory and evidence. Personality and Individual Differences, 77, 186-192.

Lukaszewski, A. W., Larson, C. M., Gildersleeve, K. A., Roney, J. R., \& Haselton, M. G. (2014). Condition-dependent calibration of men's uncommitted mating orientation: Evidence from multiple samples. Evolution and Human Behavior, 35, 319-326.

Maestripieri, D., Roney, J. R., DeBias, N., Durante, K. M., \& Spaepen, G. M. (2004). Father absence, menarche, and interest in infants among adolescent girls. Developmental Science, 7, 560-566.

Manson, J. H. (2015). Life history strategy and the HEXACO personality dimensions. Evolutionary Psychology, 13, 48-66.

McCrae, R. R., Yamagata, S., Jang, K. L., Riemann, R., Ando, J., ..., Spinath, F. M. (2008). Substance and artifact in the higher-order factors of the big five. Journal of Personality and Social Psychology, 95, 442-455.

McCullough, M. E., Pedersen, E. J., Schroder, J. M., Tabak, B. A., \& Carver, C. S. (2012). Harsh childhood environmental characteristics predict exploitation and retaliation in humans. Proceedings of the Royal Society B, 280, 20122184.

McGowan, P. O., Sasaki, A., D’Alessio, A., Dymov, S., Labonte, B., ... \& Meaney, M. J. (2009). Epigenetic regulation of the glucocorticoid receptor in human brain associates with child abuse. Nature Neuroscience, 12, 342-348.

Nettle, D., Frankenhius, W. E., \& Rickard, I. J. (2013). The evolution of predictive adaptive responses in human life history. Proceedings of the Royal Society of London B, 280, 20131343.

Pedersen, E. J., Forster, D. E., \& McCullough, M. E. (2014). Life history, code of honor, and emotional responses to inequality in an economic game. Emotion, 15, 920-929.

Penke, L. (2011). Bridging the gap between modern evolutionary psychology and the study of individual differences. In D. M. Buss \& P. $\mathrm{H}$. Hawley (Eds.), The evolution of personality and individual differences (pp. 243-279). Oxford: Oxford University Press.

Pierce, G. R., Sarason, I. G., \& Sarason, B. R. (1991). General and relationship-based perceptions of social support: Are two constructs better than one? Journal of Personality and Social Psychology, 61, 1028-1039.

Plomin, R., DeFries, J. C., Knopik, V. S., \& Neiderhiser, J. M. (2013). Behavioral genetics (6th edn). New York: Worth Publishers.

Price, M. E., \& Van Vugt, M. (2014). The evolution of leader-follower reciprocity: The theory of service-for-prestige. Frontiers in Human Neuroscience. doi:10.3389/fnhum.2014.00363. 
Raby, K. L., Roisman, G. I., Fraley, R. C., \& Simpson, J. A. (2015). The enduring predictive significance of early maternal sensitivity: Social and academic competence through age 32 years. Child Development. doi: $10.1111 / \mathrm{cdev} .12325$.

Roff, D. A. (2002). Life history evolution. Sunderland: Sinauer.

Rushton, J. P., Bons, T. A., \& Hur, Y. (2008). The genetics and evolution of the general factor of personality. Journal of Research in Personality, 42, 1173-1185.

Service, S. K., Verweij, K. J. H., Lahti, J., Congdon, E., ..., Freimer, M., B. (2012). A genome-wide meta-analysis of association studies of Cloninger's temperament scales. Translational Psychiatry, 2, e116.

Sitser, T., van der Linden, D., \& Born, M. (2013). Predicting sales performance criteria with personality measures: The use of the general factor of personality, the big five, and narrow traits. Human Performance, 26, 126-149.

Sugiyama, L. S., \& Scalise-Sugiyama, M. (2003). Social roles, prestige, and health risk: Social niche specialization as a risk-buffering strategy. Human Nature, 14, 165-190.

Tooby, J., \& Cosmides, L. (1990). On the universality of human nature and the uniqueness of the individual: The role of genetics and adaptation. Journal of Personality, 58, 17-67. van der Linden, D., Scholte, R. H. J., Cillessen, A. H. N., Nijenhuis, J. T., $\&$ Segers, E. (2010a). Classroom ratings of likeability and popularity are related to the big five and the general factor of personality. Journal of Research in Personality, 44, 669-672.

van der Linden, D., te Nijenhuis, J., \& Bakker, A. B. (2010b). The general factor of personality: A meta-analysis of big five intercorrelations and a criterion-related validity study. Journal of Research in Personality, 44, 315-327.

van der Linden, D., Figueredo, A. J., de Leeuw, R. N. H., Scholte, R. H. J., \& Engels, R. C. M. E. (2012). The general factor of personality (GFP) and parental support: testing a prediction from life history theory. Evolution and Human Behavior, 33, 537-546.

Vigil, J. M., Geary, D. C., \& Byrd-Craven, J. (2005). A life history assessment of early childhood sexual abuse in women. Developmental Psychology, 41, 553-561.

von Rueden, C. R., Gurven, M., \& Kaplan, H. (2008). The multiple dimensions of male social status in an Amazonian society. Evolution and Human Behavior, 29, 402-415.

Weaver, I. C. G., Vervoni, N., Champagne, F. A., D’Allesio, A. C., ..., Meaney, M. J. (2007). Epigenetic programming by maternal behavior. Nature Neuroscience, 7, 847-854. 